\title{
CHEMICAL ENGINEERING BUILDING OF THE COLLEGE OF SCIENCE AND TECHNOLOGY, MANCHESTER
}

$\mathrm{T}$ HE Chemical Engineering Building of the Manchester College of Science and Technology was opened officially on May 19 by Sir Alexander Fleck, chairman of Imperial Chemical Industries, Ltd. Sir Alexander, speaking to an audience of some three hundred guests from industry, referred to the continued demand for chemical engineers and illustrated the growing needs by reference to the development of technology in India and in the U.S.S.R., which he suggested would require that British industries should be maintained at the highest economic level. For this purpose it would obviously be necessary to increase and maintain our output of trained technologists, and he was therefore very happy to see so many industrial guests present at the opening ceremony, for, in the training of technologists, the closest co-operation between industry and the universities was an essential requirement. Sir Hugh
Beaver, president of the Federation of British Industries and president of the Institution of Chemical Engineers, in thanking Sir Alexander on behalf of the College and of industry, also congratulated the College authorities on providing a Department which would "surely be for all time the largest single source of chemical engineers in the British Isles". After the opening ceremony the visitors were able to inspect the laboratories and teaching facilities which had been provided in the converted cotton mill.

The main building, including basement, groundfloor and six floors, totals about 120,000 sq. $\mathrm{ft}$. in area and is separated from a five-story block containing floor area of about $32,000 \mathrm{sq}$. $\mathrm{ft}$. by the main staircase and lift shafts. The smaller area of 32,000 sq. ft. has been used to provide a variety of lecture and seminar rooms. The basement of the main building is used by the Mechanical Engineering

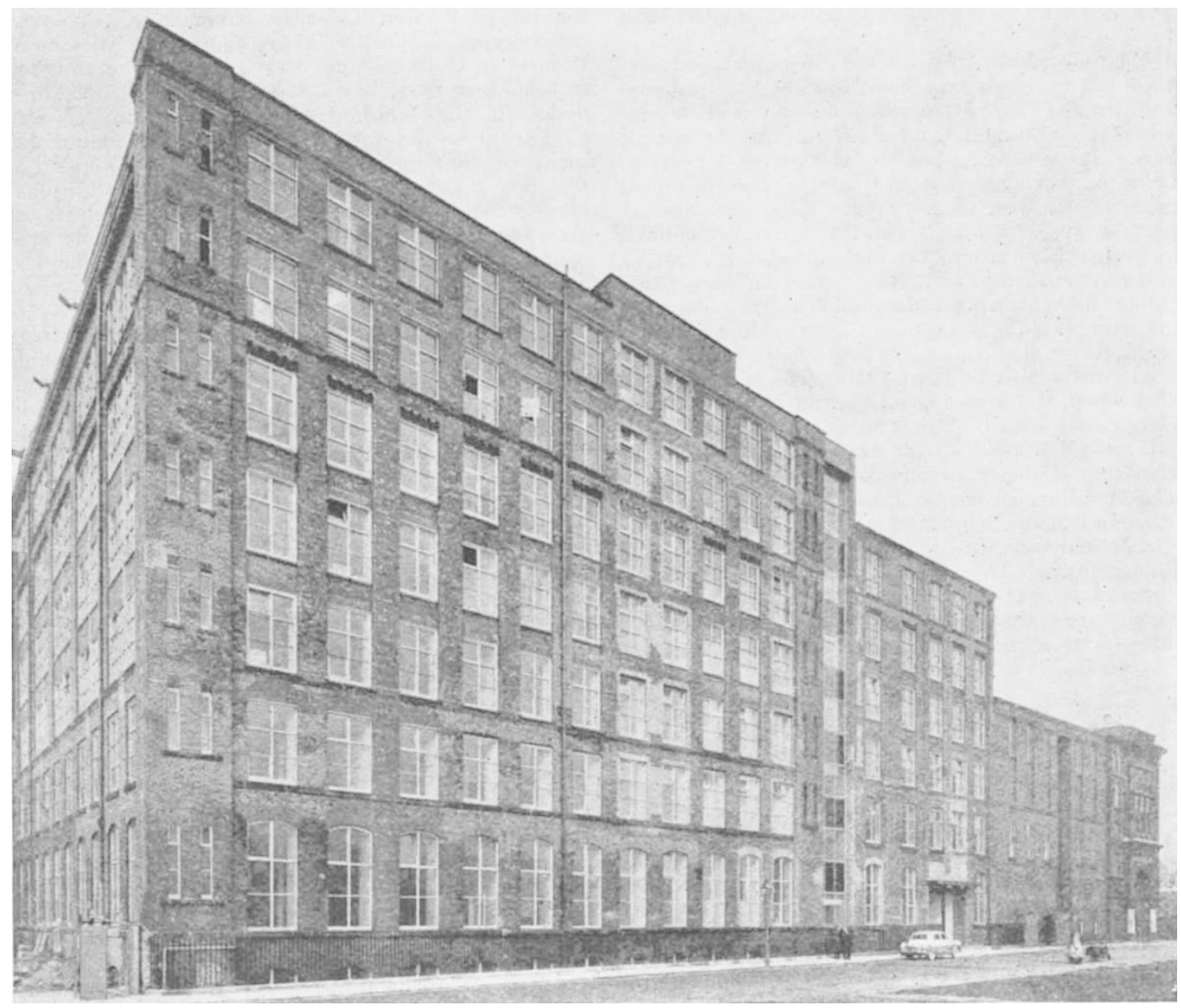

Fig. 1. Chemical Engineering Building, College of Science and Technology, Manchester 
Department for the strength of materials and fatigue testing laboratories; but at the northern end a portion of the basement, some $40 \mathrm{ft}$. deep and $100 \mathrm{ft}$. long, is used as the bottom story of the chemical engineering laboratory, which extends from the basement through to the ground-floor, thus providing access to chemical engineering pilot plants at two levels. On the ground floor the main lecture theatre and teaching laboratories of the Chemical Engineering Department are placed around a central hall in which facilities for student refreshment are provided. The main chemical engineering laboratory is entered from this hall, and on the ground-floor of the laboratory three large sections have been removed from the floor to form the two-story pits through which extraction columns, distillation columns, evaporators, etc., of the Chemical Engineering Department are built. On the northern wall of the laboratory a gallery has been erected $10 \mathrm{ft}$. above ground-level to facilitate the operation of these tall units. The first floor contains the design office of the Chemical Engineering Department, together with research laboratories, conference room, library and office facilities for the chemical engineering staff, and lecture rooms. Similar provisions are made on the upper floors, for the teaching of metallurgy and fuel technology on the second floor, for textile chemistry on the third floor, for industrial biochemistry on the fourth floor, and for machine drawing on the fifth floor.

The building, which is now fully occupied, provides a large lecture room capable of seating 130 students, sound-proofed and fitted with cinema and soundprojection equipment, and fourteen lecture rooms, varying in seating capacity of twenty to sixty, distributed throughout four floors. The chemical engineering drawing office provides adequate working space for sixty students, and the main chemical engineering laboratory provides space for a larger number of students. Further extensive pilot-plant buildings have been erected outside the main chemical engineering building on the area between the building and the River Medlock, a site previously occupied by an old cotton mill built in 1850 . The old mill was pulled down, the area concreted, and on it two large prefabricated steel buildings were erected. In these buildings pilot plants will be built by chemical engineering students as part of their training.

The Metallurgical Department, which is housed on the second floor, contains laboratories for metallurgical analysis, for general metallurgy and for metallography. The main research laboratories of the metallurgy school remain in the extension of the College, since their removal to the new building would have involved very considerable expense, which at this stage was not considered justified. Fuel technology is housed on the second floor, and in addition to the main teaching laboratories includes a number of research laboratories in which the special apparatus required for the investigation of combustion and the analysis of combustion products is housed.

The Textile Chemistry Laboratories on the fourth floor, in addition to providing laboratories for the study of the chemistry of textiles, also provide physical laboratories for the study of the physical properties of textile materials, microscopic analysis and the study of elastomers and plastics, and a number of smaller laboratories in which the research school of the Department will be housed. The Industrial Biochemistry Department on the fourth floor contains, in addition to two large teaching laboratories, several large research laboratories, a media room, an autoclave room, two constant-temperature rooms and one cold room, and each of the laboratories has an inoculation room. The large drawing office on the fifth floor has provision for three hundred students working at one time, although it is divided into rooms by partitions which split the classes into smaller groups.

The project was commenced in May 1956 when the University Grants Committee gave permission for the purchase of the existing cotton mill and for its conversion to a Department of Chemical Engineering. Work on the conversion was commenced in October 1956 and was in part completed by October 1957, when teaching in the first three floors of the building begen. The project was completed within fifteen months of the commencement of building operations and has provided a teaching space of 120,000 sq. ft. and additional lecture rooms and seminar rooms of 32,000 sq. ft. at an approximate cost of $£ 488,000$. With this provision the Chemical Engineering Department has expanded from a student intake of twenty-eight students per annum to sixty students in 1957--58, and from 1958-59 it is proposed to accept 120 students per annum. This expansion has been made possible by a corresponding expansion in the teaching staff of the Department, which has grown from a total of six in 1955 to twenty in 1958 . The postgraduate research has shown a similar increase, and the visitors to the chemical engineering building were able to see something of the research activities now being carried out in the chemical engineering school. These include studies on mass transfer processes, investigations into the composition of petroleum, studies of corrosion and of the properties of certain protective coatings, the properties of a variety of tower packings and investigations of distillation at reduced pressures.

\section{THE RADIO RESEARCH STATION, SLOUGH}

\footnotetext{
$\mathrm{O}^{\mathrm{N}}$ May 20, members of the Radio Research Board visited the Radio Research Station, one of the establishments of the Department of Scientific and Industrial Research, to inspect the work in progress. On this and the following day, several hundred visitors were invited to see various exhibits and demonstrations at the Station, the new buildings of which were formally opened in June 1957 (see Nature, $180,163 ; 1957)$.
}

The Radio Research Station conducts an extensive programme of research in the fields of radio-wave propagation and allied subjents for which adequate provision is not made elsewhere in Britain. Advice on the nature and extent of this programme is given to the Department by its Radio Research Board, which is an independent body comprising members from industry and the universities, assisted by assessors from the main Government departments 